\title{
Correlation of Process Parameters with Mechanical Properties of Laser Sintered PA12 Parts
}

\author{
Eva C. Hofland, ${ }^{1}$ Ismet Baran, ${ }^{2}$ and Dagmar A. Wismeijer ${ }^{3}$ \\ ${ }^{1}$ Oceanz, Maxwellstraat 21, 6716 BX Ede, Netherlands \\ ${ }^{2}$ Faculty of Engineering Technology, University of Twente, 7500 AE Enschede, Netherlands \\ ${ }^{3}$ TNO, Equipment of Additive Manufacturing, de Rondom 1, 5612 AP Eindhoven, Netherlands \\ Correspondence should be addressed to Ismet Baran; i.baran@utwente.nl
}

Received 7 November 2016; Revised 11 January 2017; Accepted 6 February 2017; Published 28 February 2017

Academic Editor: Gianluca Percoco

Copyright (C) 2017 Eva C. Hofland et al. This is an open access article distributed under the Creative Commons Attribution License, which permits unrestricted use, distribution, and reproduction in any medium, provided the original work is properly cited.

Selective laser sintering (SLS) is an additive manufacturing technique that enables the production of customized, complex products. SLS has proven itself a viable prototyping tool and production method for noncritical products. The industry has picked up on the potential of SLS, which raised the question whether it is possible to produce functional products with reproducible mechanical properties for application in critical sectors. Properties of SLS parts highly depend on the applied process settings. Hence, present work examined the influence of key process parameters (preheating temperature, laser power, scan spacing, scan speed, layer thickness, and part build orientation) on the properties (tensile strength, tensile modulus, elongation at break, and part density) of SLS produced parts. A design of experiments (DoE) approach was used to plan the experiments. Test samples according to DIN EN ISO 527-2 were produced on a sintering system (EOSINT P395) using polyamide 12 powder (EOS PA2200). Regression models that describe the relation between the process settings and resulting part properties were developed. Sensitivity analysis showed that mechanical properties of sintered parts were highly affected by layer thickness and scan spacing variations.

\section{Introduction}

Selective laser sintering (SLS) is an additive manufacturing technique which uses a laser beam to locally melt polymer powder to build products in a layer by layer fashion.

During the past years, laser sintering of polymers has developed and grown into a viable prototyping tool and production method for customized, noncritical products (e.g., figurines, phone cases, and jewellery). The industry has seen the potential of selective laser sintering, which raised the question whether it is possible to apply SLS to produce fully functional products with reproducible mechanical properties. SLS has the potential to become the number one choice for small series production of high strength polymer parts. Comparison between conventional injection moulding and SLS has shown that up to 1,000 parts SLS is more economical [1]. A schematic visualization of the SLS fabrication process and an overview of the production process are given in Figures 1 and 2.

The important parameters that affect the energy input during sintering and thereby affect the resulting part properties of the sintered products are laser power, scan speed, scan spacing, layer thickness, and preheating temperature. In addition to the energy related parameters, part build orientation has proven to have an important influence on the product quality as well.

Caulfield et al. [2] investigated the effect of the energy input and the part build orientation on the mechanical behaviour of polyamide parts produced on a DTM Sinterstation. An increase in laser power resulted in an increase of the energy input, which was shown to have a positive effect on the apparent density of sintered parts. In turn, a high part density was correlated with high values for the mechanical properties of sintered parts (yield strength, tensile modulus, fracture strength, and elongation at break). However, the results of Caulfield et al. [2] indicated that an optimum energy input exists. Above a certain value, the increase of strength and stiffness flattens out or even decreases with increasing energy input. According to both Caulfield et al. [2] and Goodridge et al. [3] high laser power values can result in excess heat which can result in damaged or burnt 


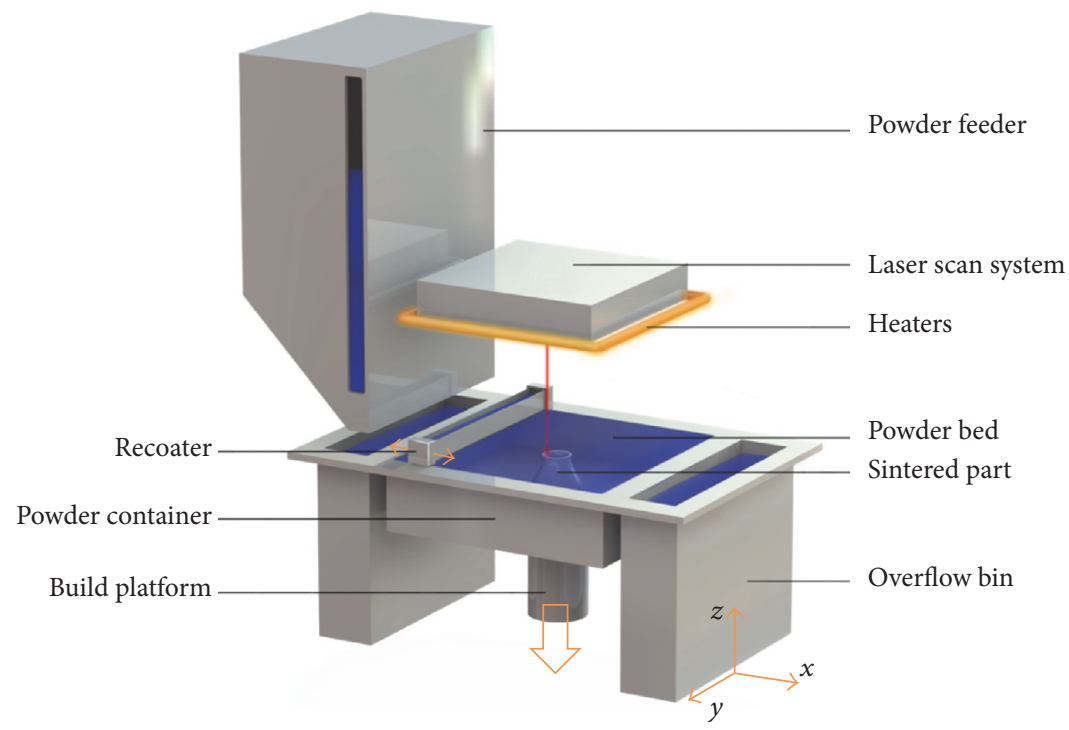

FIgURE 1: Visualization of the SLS fabrication process.

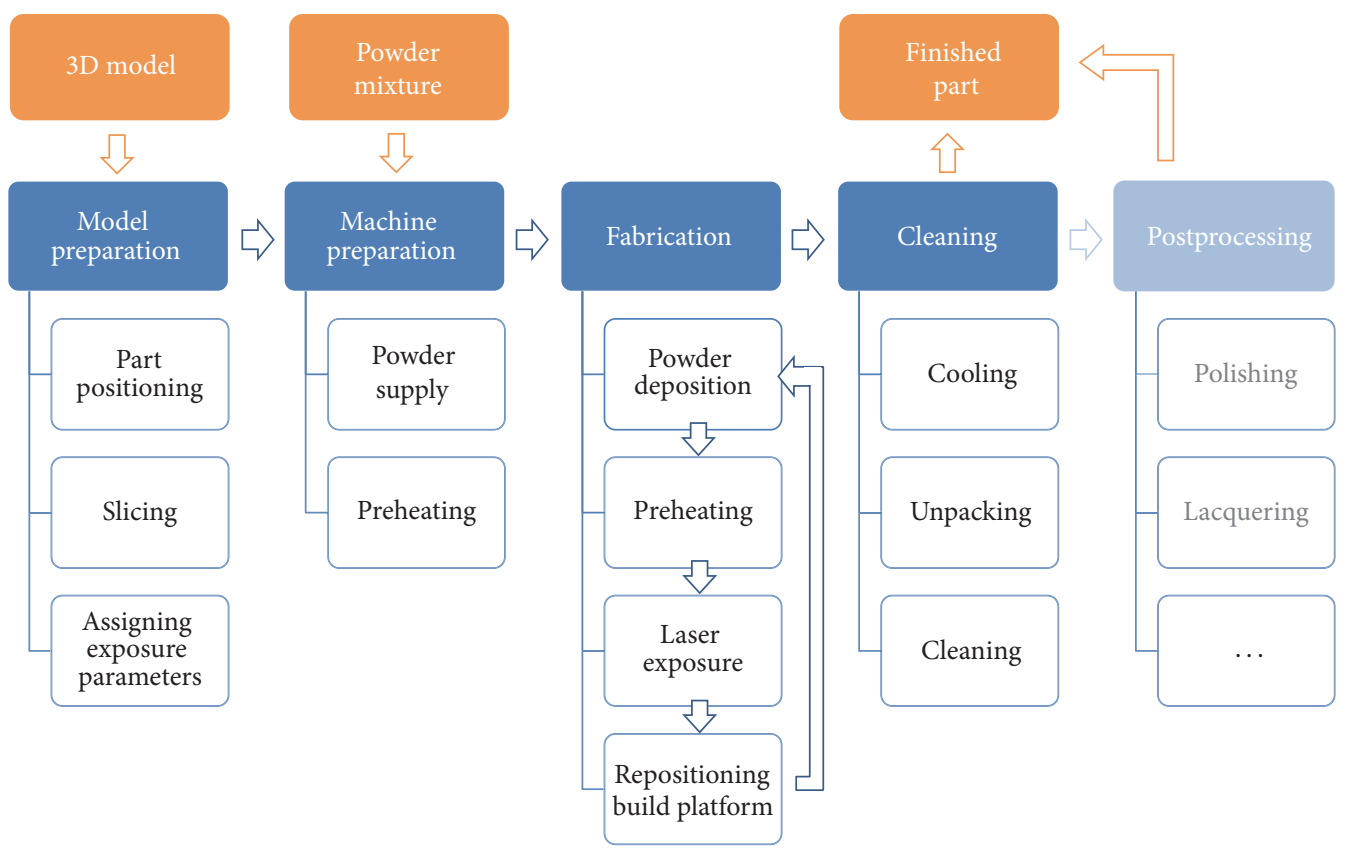

FIGURE 2: Schematic overview of the complete SLS production process.

powder, shear stresses between layers, and possible part distortion.

A more extensive study using response surface modelling (RSM) to determine the correlation between process parameters and part properties in laser sintering was performed by Wegner and Witt [4]. Wegner and Witt [4] studied the effect of the laser power, scan spacing, scan speed, preheating temperature, and layer thickness on the tensile strength, tensile modulus, elongation at break, and part density of polyamide parts produced on a high-speed DTM Sinterstation. The scan spacing was varied between $0.25 \mathrm{~mm}$ and $0.45 \mathrm{~mm}$ and the scan speed varied between 5500 and $11000 \mathrm{~mm} / \mathrm{s}$ This study confirmed that there is indeed an optimum energy input: after a certain energy input value, the part properties stabilized or even decreased. In addition, Wegner and Witt [4] also confirm that there is a positive relation between the laser power and the part properties. However, based on the coefficients in the regression equations, the influence of the laser power was relatively small. More important parameters were found to be the scan spacing and layer thickness, which were not investigated by Caulfield et al. [2].

Negi et al. [5] performed both RSM and sensitivity analysis to investigate the effect of several process parameters (preheating temperature, laser power, scan speed, and scan 
spacing) on the properties (tensile strength, elongation, yield strength, and tensile modulus) of glass filled polyamide parts produced with the SLS on an EOS sintering system. The scan speed varied between 2500 and $4500 \mathrm{~mm} / \mathrm{s}$. They found that all four parameters have a significant effect on the mechanical properties of sintered parts of which scan speed and scan spacing had the largest effect. Negi et al. [5] confirmed the results of Caulfield et al. [2] and Wegner and Witt [4] that the mechanical properties of sintered parts increase with an increase of laser power and preheating temperature and decrease with an increase in scan speed and scan spacing. The scan speed and scan spacing were found to have the largest (positive) effect on the properties, while the preheating temperature and laser power have a relatively small influence on the part properties. Similar results were found in Tontowi et al. [6] and Griessbach et al. [7]. They found that increasing the preheating temperature has a positive effect on the tensile properties and part density. It should be noted that Negi et al. [5] used a different material and did not include layer thickness and part build orientation.

Pilipović et al. [8] and Wegner and Witt [4] showed that the layer thickness has a very large influence on the part properties. An increase of layer thickness resulted in a decrease of the part density and the tensile properties and therefore recommend to strive for a layer thickness as thin as possible. Thinner layers, however, significantly increase total build time. Berretta et al. [9] recommended a minimal layer thickness of at least two times the average particle size.

Ajoku et al. [10] found that parts built parallel to the layer orientation $\left(0^{\circ}\right)$ had better tensile properties (higher tensile strength, Young's modulus, and elongation at break) than parts built perpendicular to layer orientation $\left(90^{\circ}\right)$. Caulfield et al. [2] found similar results. They concluded that the $90^{\circ}$ orientation resulted in a better geometric accuracy but in a lower density, yield strength, tensile modulus, and fracture strength than the $0^{\circ}$ oriented parts.

Based on the aforementioned literature, the expectation is that the best properties are obtained with a high preheating temperature, high laser power, a small scan spacing, a low scan speed, a layer thickness as thin as possible, and a part build orientation parallel to the layer orientation.

Although the aforementioned studies provide relationships between process parameters and part properties for PA12, the sensitivity for these parameters has not been addressed quantitatively yet. In addition, studies on PA12 were done on DTM Sinterstations only, which may make broader application of the results difficult. Therefore the present work examines the relation between the process parameters (laser power, scan speed, scan spacing, layer thickness, and preheating temperature) and part properties (the tensile strength, tensile modulus, elongation at break, and part density) of horizontally and vertically built samples using RSM and sensitivity analysis. The aim is to extend process knowledge on selective laser sintering of polymers, increase process control, and enable part property prediction by carrying out a comprehensive analysis of SLS which has not been considered up to now. The ultimate goal is to contribute to the progression of SLS to a full (rapid) manufacturing method (beyond prototyping and visualization) that

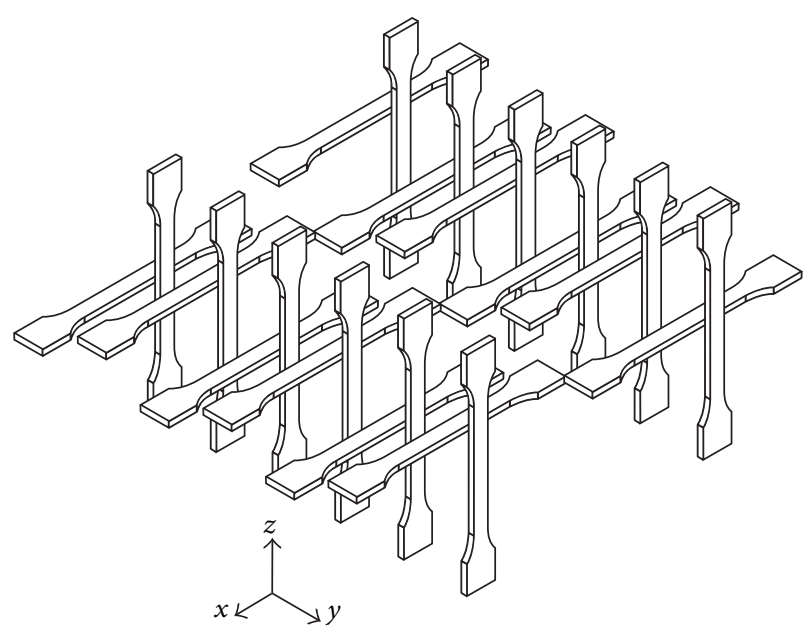

FIGURE 3: Example of an assembly with various tensile samples. Horizontally built samples are oriented parallel to the $x y$-plane; vertically built samples are oriented along the $z$-axis.

enables the production of fully functional, critical products. Present work examined and quantified the relations between the input parameters and the part properties for polyamide 12 powder (EOS PA2200) on the EOSINT P395 sintering system for two build orientations $\left(0^{\circ}\right.$ and $\left.90^{\circ}\right)$. A fractional factorial design of experiments was used to plan the SLS experiments and response functions were created to study the individual and interaction effects between input parameters and the output (part properties). Sensitivity analysis was used to investigate the absolute effect of each input parameter using Monte Carlo simulation and linear correlation coefficients.

\section{Materials and Experiments}

2.1. Material. The material used for examination was polyamide 12 powder, PA2200, supplied by EOS $\mathrm{GmbH}$ (Germany). According to the powder manufacturer, the average particle size of the powder is $56 \mu \mathrm{m}$ and the bulk density is $0.45 \mathrm{~g} / \mathrm{cm}^{3}$. All samples were printed with refreshed PA2200. Refreshed PA2200 is a mixture of virgin (completely new) PA2200 powder and used PA2200 powder in a 1:1 ratio. The proper ratio of new and used powder is produced by the EOS IPCM P mixing system. This mixing system also controls the humidity which is brought to $30 \%$ relative humidity.

2.2. Experimental Setup. To be able to determine the properties of sintered objects, test samples were produced. All test samples were dog-bone tensile samples as defined in DIN EN ISO 527-2. All samples were produced on the EOSINT P395 SLS machine (EOS GmbH, Germany). This commercially available sintering apparatus is equipped with a $50 \mathrm{~W} \mathrm{CO}$ laser and has a maximum building volume of $330 \times 330 \times$ $640 \mathrm{~mm}$ (length $\times$ width $\times$ height).

Samples were printed both horizontally and vertically as schematically depicted in Figure 3. 
The part properties selected for evaluation were the part density, the tensile strength, the tensile modulus, and the elongation at break. The tensile properties were determined at $5 \mathrm{~mm} / \mathrm{min}$ strain rate with a universal testing machine (TesT tensile tester). The clamping device was produced to match the dimensions of the tensile samples. This enabled reproducible clamping and prevented slip. The resulting force-displacement data was used to calculate the tensile strength $[\mathrm{MPa}]$ and elongation at break [\%] of each sample. To be able to calculate the tensile modulus [MPa], the forcedisplacement data was translated into a stress-strain curve. Stress was defined as the force divided by the initial crosssectional area as measured per sample. Strain was defined as the measured displacement divided by the (measured) initial length of the sample.

The mass of each sample was determined with a Mettler AT 200 scale, with a precision of $0.001 \mathrm{~g}$. The dimensions of each sample were measured using a digital calliper with a precision of $0.01 \mathrm{~mm}$. This data was used to determine the part density per sample.

All values beyond the upper and lower fence were considered outliers and were excluded from further analysis.

\section{Design of Experiments and Analysis}

3.1. Parameter Selection. The parameters selected for investigation were the preheating temperature $\left[{ }^{\circ} \mathrm{C}\right]$, laser power [W], scan speed [ $\mathrm{mm} / \mathrm{s}]$, scan spacing $[\mathrm{mm}]$, layer thickness $[\mathrm{mm}]$, and the part build orientation $\left(0^{\circ}\right.$ or $\left.90^{\circ}\right)$.

3.2. Total Energy Input. A relation between three of the main process parameters of selective laser sintering has been described in an energy density equation which was introduced by Nelson [11]. Equation (1) specifies the energy density $\left(E_{d}\left[\mathrm{~J} / \mathrm{mm}^{2}\right]\right)$ as a function of the laser power $(P)$, scan speed $(v)$, and scan spacing $(s)$. The energy density represents the amount of energy supplied to the powder particles per unit area of the powder bed surface [2].

$$
E_{d}=\frac{P}{s \cdot v} \text {. }
$$

Thijs et al. [12] adapted this equation by adding the layer thickness as a fourth parameter thus describing the energy input per unit of volume as follows:

$$
V E_{d}=\frac{P}{s \cdot v \cdot t} .
$$

The former equations do not, however, fully capture the energy input needed to obtain powder melt. To this end, a measure for the total energy input per unit of volume has been defined by adding the energy input from the preheating phase to the volumetric energy density equation (2). This preheating energy input is defined as follows:

$$
E_{\mathrm{pr}}=c_{p} \cdot \rho \cdot T_{\mathrm{pr}}
$$

Combining the volumetric energy density and the preheating energy captures all the energy related process parameters
(4) and determines how much powder will melt. The total energy input $E_{\text {in }}$ is expected to correlate with the resulting part properties.

$$
E_{\text {in }}=\frac{P}{s \cdot v \cdot t}+c_{p} \cdot \rho \cdot T_{\mathrm{pr}}
$$

where $E_{\text {in }}\left[\mathrm{J} / \mathrm{mm}^{3}\right]$ is total volumetric energy input, $P[\mathrm{~W}]$ is laser power, $s[\mathrm{~mm}]$ is scan spacing, $v[\mathrm{~mm} / \mathrm{s}]$ is scan speed, $t$ $[\mathrm{mm}]$ is layer thickness, $c_{p}\left[\mathrm{~J} / \mathrm{g}^{\circ} \mathrm{C}\right]$ is specific heat capacity, $\rho\left[\mathrm{g} / \mathrm{mm}^{3}\right]$ is powder density, and $T_{\mathrm{pr}}\left[{ }^{\circ} \mathrm{C}\right]$ is preheating temperature.

In the remainder of this article, the energy term $\left(E_{\mathrm{in}}\right)$ is used to capture the five process parameters in one term.

The specific heat capacity and the powder density are material constants. According to the EOS material data sheet the powder density of EOS PA2200 is $0.45 \mathrm{~g} / \mathrm{cm}^{3}$. According to the additive manufacturing company Cresilas, the specific heat capacity of PA12 is $1.64 \mathrm{~J} / \mathrm{g}^{\circ} \mathrm{C}$. Therefore, these values are used in the calculation of $E_{\text {in }}$.

3.3. Process Settings. A design of experiments (DoE) approach has been used to determine the correlation between aforementioned process parameters (in total 5) and part properties (in total 4) for two part build orientations.

To be able to investigate the linear and interaction effects of five factors simultaneously while minimizing the amount of print jobs, the choice has been made to use the one-half fractional factorial design of experiments with five factors and two levels ( $2^{5-1}$ fractional factorial design). This allowed the determination of the main effects and two-factor interactions [13]. To be able to detect nonlinear effects, four centre points were added. This resulted in sixteen different parameter sets which were produced in four different print jobs. The four centre point sets were printed in four individual print jobs. Each parameters set was used to print 12 horizontally built and 12 vertically built tensile samples. This resulted in a total amount of 480 tensile samples.

3.4. Response Functions. The (fractional) factorial design resulted in a series of samples produced with different parameter sets and accompanying response(s). Based on this data, response functions were created. For the selected design, these equations are polynomial functions consisting of the overall mean response, the main effect for each factor, and the two-way interaction between factors $[14,15]$. This resulted in the following function in which $Y$ is the response value (output parameter) and $X_{n}$ are the input parameters:

$$
Y=c_{0}+\sum_{i} c_{i} X_{i}+\sum_{i} c_{i i} X_{i}^{2}+\sum_{i<j} c_{i j} X_{i} X_{j},
$$

where $c_{0}$ is the overall mean response, $c_{i}$ is the linear main effect for factor $(i=1,2, \ldots, n), c_{i i}$ is the quadratic main effect for factor $(i=1,2, \ldots, n)$, and $c_{i j}$ is the two-way interaction between the $i$ th and $j$ th factors.

Regression analysis was used to determine which effects and interactions have a significant influence on the response 
TABLE 1: Summarized results of the design of experiments: energy input and resulting part properties for all sample sets. The maximum obtained values are highlighted in bold. " $x$ " denotes sample sets that were excluded from the research.

\begin{tabular}{|c|c|c|c|c|c|c|c|c|c|}
\hline & $\begin{array}{c}E_{\text {in }} \\
{\left[\mathrm{J} / \mathrm{mm}^{3}\right]}\end{array}$ & $\begin{array}{l}\mathrm{TS} 0^{\circ} \\
{[\mathrm{MPa}]}\end{array}$ & $\begin{array}{c}\mathrm{EaB} 0^{\circ} \\
{[\%]}\end{array}$ & $\begin{array}{c}\text { E-modulus } 0^{\circ} \\
{[\mathrm{MPa}]}\end{array}$ & $\begin{array}{c}\text { Density } 0^{\circ} \\
{\left[\mathrm{g} / \mathrm{cm}^{3}\right]}\end{array}$ & $\begin{array}{l}\text { TS 90 } \\
{[\mathrm{MPa}]}\end{array}$ & $\begin{array}{c}\mathrm{EaB} 90^{\circ} \\
{[\%]}\end{array}$ & $\begin{array}{c}\text { E-modulus } 90^{\circ} \\
{[\mathrm{MPa}]}\end{array}$ & $\begin{array}{c}\text { Density } 90^{\circ} \\
{\left[\mathrm{g} / \mathrm{cm}^{3}\right]} \\
\end{array}$ \\
\hline 1 & 0.731 & 48.2 & 25.9 & 1961 & 0.932 & 47.1 & 11.4 & 1867 & 0.951 \\
\hline 2 & 0.391 & 43.1 & 14.5 & 1404 & 0.904 & 6.4 & 2.2 & 941 & 0.895 \\
\hline 3 & 0.331 & 30.4 & 11.9 & 1066 & 0.834 & $x$ & $x$ & $x$ & $x$ \\
\hline 4 & 0.326 & 31.5 & 8.1 & 1647 & 0.858 & 11.1 & 2.7 & 1284 & 0.853 \\
\hline 5 & 0.620 & 46.3 & 25.6 & 1664 & 0.910 & 38.7 & 8.6 & 1502 & 0.900 \\
\hline 6 & 0.609 & 49.1 & 24.1 & 2239 & 0.942 & 44.5 & 8.4 & 2004 & 0.943 \\
\hline 7 & 0.497 & 49.6 & 22.9 & 2191 & 0.953 & 46.2 & 12.1 & 2171 & 0.947 \\
\hline 8 & 0.290 & 19.1 & 10.0 & 712 & 0.748 & $\times$ & $x$ & $\times$ & $x$ \\
\hline 9 & 0.533 & 47.5 & 23.3 & 1768 & 0.920 & 51.2 & 10.6 & 1589 & 0.915 \\
\hline 10 & 0.524 & 50.1 & 23.3 & 1806 & 0.949 & 42.6 & 8.3 & 1647 & 0.947 \\
\hline 11 & 0.433 & 49.6 & 20.7 & 1787 & 0.947 & 43.0 & 8.0 & 1666 & 0.942 \\
\hline 12 & 0.263 & 18.3 & 9.3 & 719 & 0.740 & $x$ & $\times$ & $x$ & $\times$ \\
\hline 13 & 0.866 & $x$ & $x$ & $x$ & $x$ & 45.9 & 15.6 & 1840 & 0.933 \\
\hline 14 & 0.452 & 47.4 & 23.5 & 1642 & 0.928 & 34.2 & 6.9 & 1440 & 0.914 \\
\hline 15 & 0.377 & 45.3 & 17.2 & 1577 & 0.916 & 25.5 & 4.1 & 1383 & 0.905 \\
\hline 16 & 0.372 & 47.2 & 15.5 & 1672 & 0.934 & 29.7 & 5.2 & 1409 & 0.920 \\
\hline 17 & 0.424 & $x$ & $x$ & $x$ & $x$ & $x$ & $x$ & $x$ & $x$ \\
\hline 18 & 0.424 & 46.7 & 18.9 & 1610 & 0.931 & 31.2 & 5.5 & 1381 & 0.917 \\
\hline 19 & 0.424 & 47.5 & 21.2 & 1636 & 0.935 & 30.2 & 4.9 & 1389 & 0.917 \\
\hline 20 & 0.424 & 47.6 & 19.1 & 1681 & 0.938 & 31.4 & 5.2 & 1363 & 0.916 \\
\hline
\end{tabular}

values and therefore needed to be included in the equation. Determining the significance of a factor and the development of the resulting regression equations have been done with the Multiple Regression Assistant of Minitab 17 Statistical Software [15].

Highly correlated variables can cause instability of the regression equations. To remove multicollinearity, all factors were standardized by subtracting the mean and dividing by the standard deviation. In addition, standardization of the factors reduced the chance of adding (higher order) terms unnecessary.

3.5. Sensitivity Analysis. The regression equations were used to determine linear correlation coefficients between the process parameters and the resulting part properties. The corresponding sensitivity (in percentage) was determined as well.

The regression equations were run through a Monte Carlo simulation (MCS). MCS is a sampling technique which randomly selects input values to simulate a print job [16]. MCS was run ten times per equation in order to reduce the statistical effects. One run simulated 10.000 print jobs. The sample data was selected randomly for five input parameters within a limited range. The random selection was done using the Latin Hypercube Sampling (LHS) technique in order to guarantee no overlapping among the sample points.

The correlation between an input variable (e.g., laser power) and an output variable (e.g., tensile strength) was calculated with the following equation:

$$
r_{p}=\frac{\sum_{i}^{n}\left(x_{i}-\bar{x}\right)\left(y_{i}-\bar{y}\right)}{\sqrt{\sum_{i}^{n}\left(x_{i}-\bar{x}\right)^{2}} \sqrt{\sum_{i}^{n}\left(y_{i}-\bar{y}\right)^{2}}},
$$

where $r_{p}$ is the correlation coefficient between the two variables $x$ and $y, n$ is the sample size, and $\bar{x}$ and $\bar{y}$ are the mean of the sample data $x$ and $y$, respectively [16].

\section{Results and Discussion}

4.1. Part Property Quantification. As aforementioned, a total of 480 tensile samples were produced and tested as specified. The results are summarized in Table 1. Due to confidentiality, the utilized range of the process parameters is not presented in this work; however the results are discussed based on $E_{\text {in }}$ as defined in (4).

The maximum obtained values with PA2200 of horizontally built samples for the tensile strength (TS), tensile modulus (E-modulus), elongation at break (EaB), and part density were, respectively, $50.1 \mathrm{MPa}, 2239 \mathrm{MPa}, 25.9 \%$, and $0.953 \mathrm{~g} / \mathrm{cm}^{3}$. The maximum obtained values of vertically built samples were $51.2 \mathrm{MPa}, 2171 \mathrm{MPa}, 15.6 \%$, and $0.951 \mathrm{~g} / \mathrm{cm}^{3}$. The corresponding $E_{\text {in }}$ values can be seen in Table 1. " $\times$ " denotes sample sets that were excluded from the research since the applied settings did not result in successfully built samples. Sample set 17 was excluded from investigation due to incorrect exposure settings.

Injection grade PA12 was found to have a tensile strength between 45 and $55 \mathrm{MPa}$, a tensile modulus of 1080 to $1350 \mathrm{MPa}$, an elongation of 41 to $59 \%$, and a density between 1.00 and $1.02 \mathrm{~g} / \mathrm{cm}^{3}$ (unfilled rigid PA12, source: 
TABLE 2: Comparison of maximum obtained values of present work with literature.

\begin{tabular}{|c|c|c|c|c|c|c|c|c|c|c|}
\hline & & \multirow{2}{*}{ Applied $E_{\text {in }}$ values } & \multicolumn{2}{|c|}{ TS $[\mathrm{MPa}]$} & \multicolumn{2}{|c|}{ E-modulus [MPa] } & \multicolumn{2}{|c|}{$\mathrm{EaB}[\%]$} & \multicolumn{2}{|c|}{ Density $\left[\mathrm{g} / \mathrm{cm}^{3}\right]$} \\
\hline & & & $0^{\circ}$ & $90^{\circ}$ & $0^{\circ}$ & $90^{\circ}$ & $0^{\circ}$ & $90^{\circ}$ & $0^{\circ}$ & $90^{\circ}$ \\
\hline Present work & PA2200, EOS system & $0.26-0.86 \mathrm{~J} / \mathrm{mm}^{3}$ & 50.1 & 51.2 & 2239 & 2171 & 25.9 & 15.6 & 0.953 & 0.951 \\
\hline Caulfield et al. [2] & DuraForm PA, DTM Sinterstation & $0.19-0.36 \mathrm{~J} / \mathrm{mm}^{3}$ & 48 & 44 & 1100 & 900 & 18 & 15 & 1.05 & 0.95 \\
\hline Wegner and Witt [4] & PA2200, DTM Sinterstation & $0.23-0.67 \mathrm{~J} / \mathrm{mm}^{3}$ & 51.3 & 48.9 & 1758 & 1692 & 21.1 & 13.7 & 0.998 & - \\
\hline Negi et al. [5] & Glass filled PA, EOS system & $0.23-0.71 \mathrm{~J} / \mathrm{mm}^{3}$ & 39.1 & - & 2460 & - & 16.4 & - & - & - \\
\hline
\end{tabular}

CES EduPack, 2015). Comparing injection moulded PA12 with laser sintered PA2200 showed that the laser sintered material has a comparable strength, a significantly higher tensile modulus, much lower elongation at break, and a comparable part density.

The difference in tensile modulus and elongation at break is most likely related to the difference in cooling between the two manufacturing techniques. Injection moulded products are cooled within seconds, while SLS parts take several hours to cool. The cooling rate determines the ratio between crystalline and amorphous regions of the polymer structure, which in turn affects the elastic and plastic behaviour of the material [17].

The (visco-) elastic behaviour of a semicrystalline polymer is determined by the deformation caused by straining the interlamellar amorphous regions enclosed by crystallites [18]. This means that a low crystallinity will result in a low Young's modulus and the higher crystallinity yields in higher modulus as the molecular chains are packed closely and parallel. However, when the amorphous regions are in their glassy state (below $T_{g}$ ) (which is the case with PA2200) Young's modulus is not determined by the crystallinity.

The plastic behaviour of a semicrystalline polymer is determined by the fine chain slip of the amorphous regions and the coarse slip between the crystallites. Fine chain slip is generally larger than the plastic deformation of crystallites [18]. This means that a low crystallinity will result in a larger elongation at break.

Several studies have confirmed that the cooling rate influenced the elongation at break of sintered parts: according to Goodridge et al. [3] and Zarringhalam et al. [19], rapidly cooled products have a higher elongation at break than slowly cooled products. In addition to a different elongation at break, it is important to know that slow cooling (higher crystallinity) results in more shrinkage [20].

Comparison of the properties of present work with the results of comparable studies as presented in literature resulted in the following observations.

Caulfield et al. [2] used significantly lower energy input values as seen in Table 2 . They found a maximum tensile strength of $48 \mathrm{MPa}$ for horizontally built samples and $44 \mathrm{MPa}$ for vertically built samples using the DuraForm ${ }^{\mathrm{TM}}$ polyamide with DTM Sinterstation. According to material data sheets, DuraForm polyamide has a tensile strength of $43 \mathrm{MPa}$ (3D Systems $\mathrm{GmbH}$ ), which means maximum strength was obtained with a relatively low energy input.

However, the maximum obtained values of the tensile modulus found in Caulfield et al. [2] were considerably lower than the values presented in material datasheets.
Caulfield et al. [2] found extremely low maximum values of $1100 \mathrm{MPa}\left(0^{\circ}\right)$ and $900 \mathrm{MPa}\left(90^{\circ}\right)$. Because not all the process parameters were given, a qualitative reason for this difference remains unknown. The deviation in tensile modulus might be related to a different cooling behaviour due to different sintering systems.

Comparison of the absolute values for the tensile strength with comparable studies as presented in literature showed that Wegner and Witt [4] found maximum values of $51.3 \mathrm{MPa}$ $\left(0^{\circ}\right)$ and $48.9 \mathrm{MPa}\left(90^{\circ}\right)$ with a volumetric energy input of approximately $0.46 \mathrm{~J} / \mathrm{mm}^{3}$. Present work found comparable maximum strength values with an energy input of $0.52 \mathrm{~J} / \mathrm{mm}^{3}$. This is another indication that different sintering systems require different energy inputs to obtain certain part properties.

Despite different energy input values, the obtained values for the elongation at break are very similar. Wegner and Witt [4] found maximum values of $21.2 \%$ for horizontally built samples and $12.9 \%$ for vertically built samples. Caulfield et al. [2] found values of $0.15\left(0^{\circ}\right)$ and $0.18\left(90^{\circ}\right)$, which means that they found higher elongation values for vertically printed samples than for horizontally built samples. Combined this indicates that the elongation at break does not depend on the energy input, but it is related to another process parameter. Since the elongation at break is highly dependent on the crystallinity of the polymer, this process parameter is most likely the cooling rate. This will be further discussed in Section 4.4.

Comparing the part density values with literature showed that the obtained values in present work were relatively low. Tontowi et al. [6] found maximum densities of approximately $0.98 \mathrm{~g} / \mathrm{cm}^{3}$, Wegner and Witt [4] reported values of $0.998 \mathrm{~g} / \mathrm{cm}^{3}$ and Caulfield et al. [2] found even higher values of $1.05 \mathrm{~g} / \mathrm{cm}^{3}$ for horizontally built samples. Since the mechanical properties of these studies are comparable or lower than the values found in the present study, the difference in density is likely to be related to differently shaped density samples. Wegner and Witt [4] and Caulfield et al. [2] both used density cubes to determine the apparent density and Tontowi et al. [6] used rectangular samples instead of dog-bone samples.

4.2. Anisotropy. Despite the high maximum value for the tensile strength of vertically built samples, the tensile strength, tensile modulus, and elongation at break of horizontally built samples were generally higher than the properties of the vertically built samples. This behaviour is a clear indication of anisotropy. Due to the layerwise building process, interfaces between layers occur. During a tensile test, the horizontally 


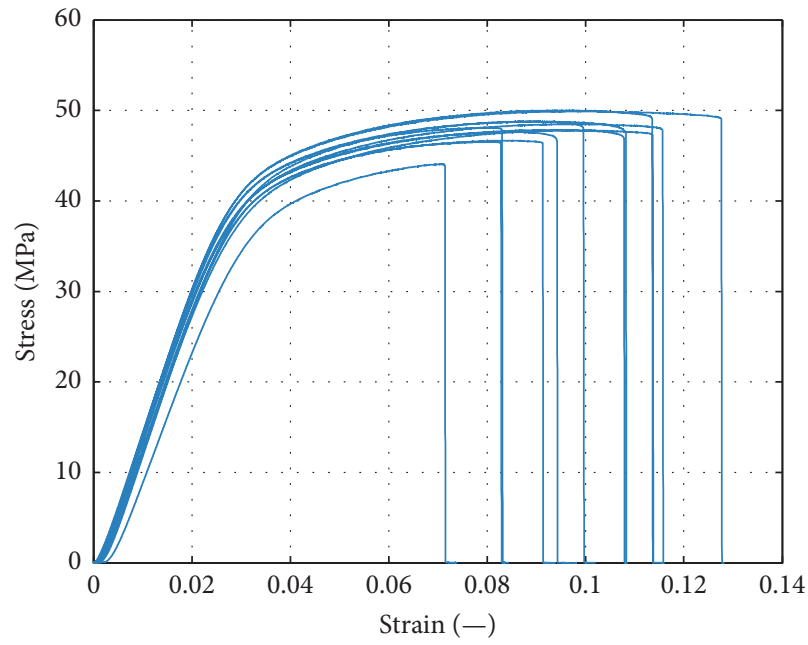

(a)

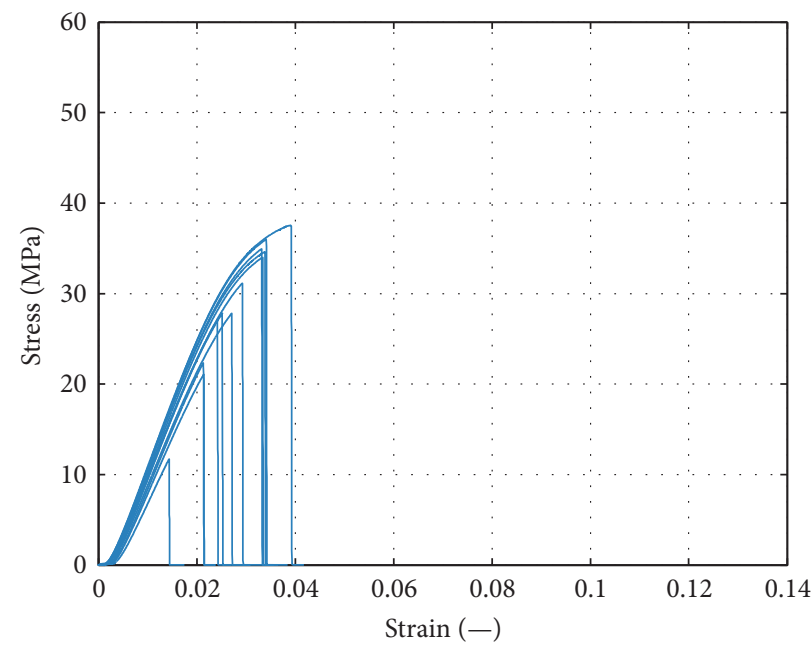

(b)

FIGURE 4: Stress-strain diagrams of a centre point sample set with an energy input of $0.424 \mathrm{~J} / \mathrm{mm}^{3}$ : horizontal (a) versus vertical (b).

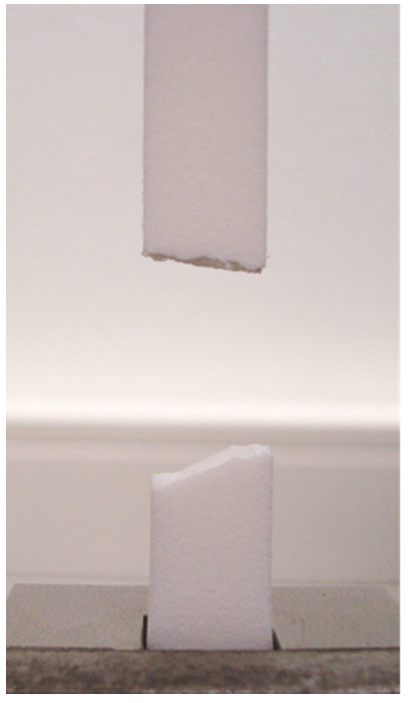

(a)

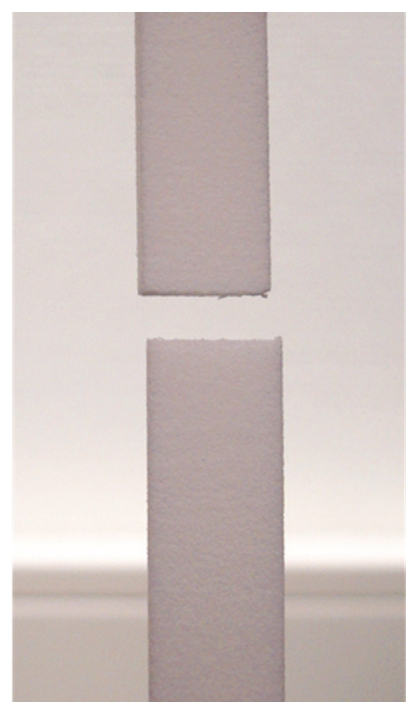

(b)

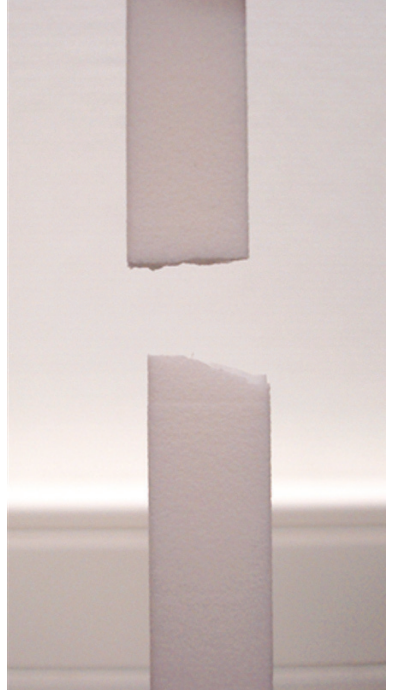

(c)

FIGURE 5: Photos of the fracture surface of tensile samples: horizontally built sample (a), vertically built sample (b), and vertically built sample produced with a high energy input (c).

built samples are loaded parallel to the layer interfaces, while the vertically built samples are loaded perpendicular to the layers. To fracture a horizontally built sample, several layers need to fail before complete failure occurs. To break a vertically built sample, only one interface needs to fail. This difference in fracture behaviour is visualized in Figure 4.

Due to this anisotropy, vertically built samples have relatively low tensile strength values with a large variation, a very low elongation at break, and lower tensile modulus values. However, when the energy input increased, the fracture behaviour of the samples became less orientation dependent and thus more isotropic (see Figure 5(c)).

4.3. Part Properties versus Energy Input. Figure 6 shows that the part properties increase with increasing energy input, until an upper limit is reached. At the other end, very low energy inputs result in low and highly variable properties (relatively large 95\% confidence intervals) suggesting that using a threshold value for energy input increases the chance of a successful build with reproducible part properties.

Besides an increase in part properties with increasing energy input, an increase in isotropy was observed. High energy input values resulted in comparable part properties for the tensile strength and tensile modulus for both build directions.

Figure 6 shows that the part density appears to be independent of build orientation.

The properties of horizontally printed samples stabilized around $0.37 \mathrm{~J} / \mathrm{mm}^{3}$, while the properties of vertically built samples stabilized around $0.46 \mathrm{~J} / \mathrm{mm}^{3}$. Above an energy input 

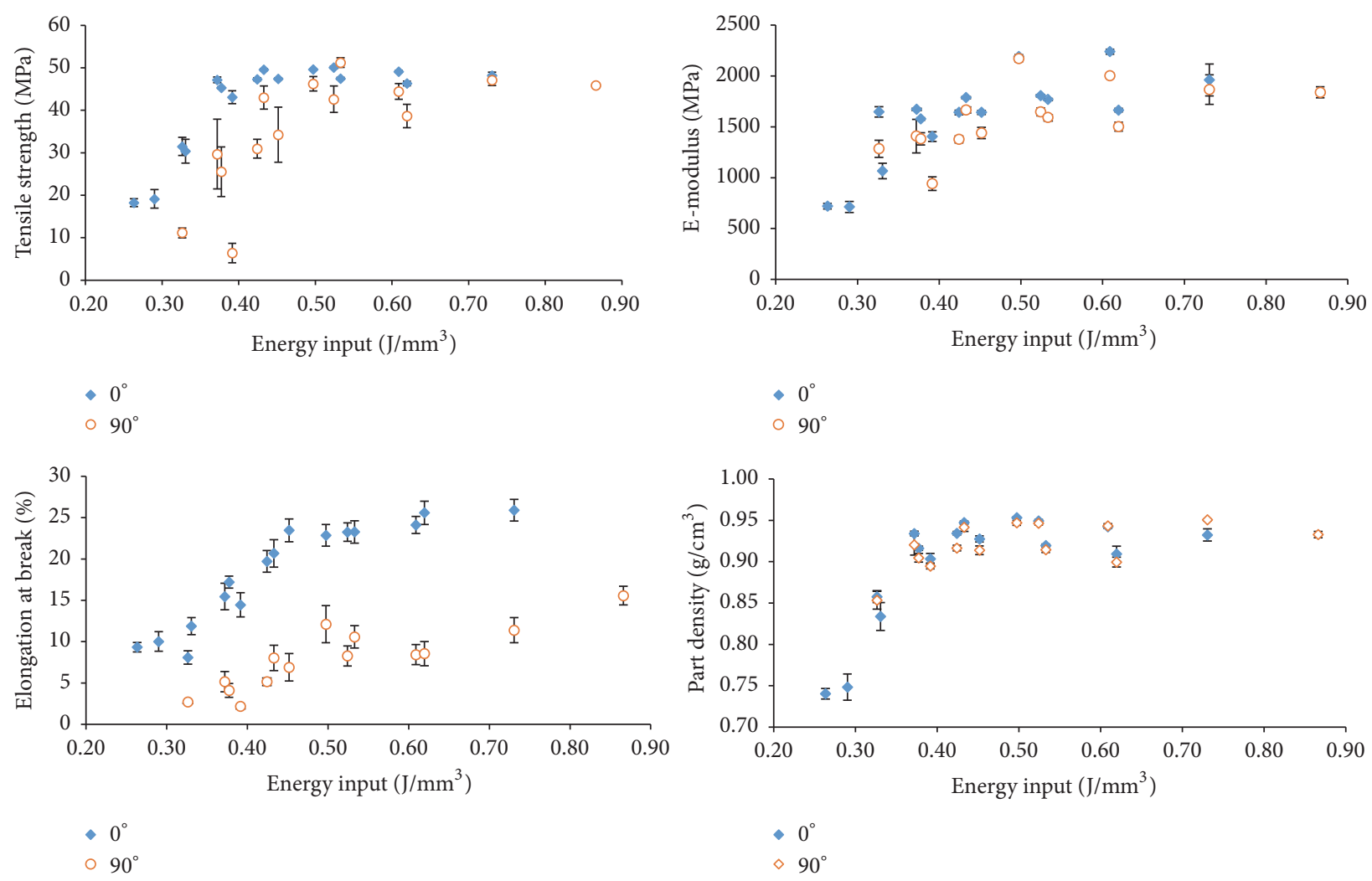

FIGURE 6: Measured values for the tensile strength, tensile modulus, elongation at break, and part density at the investigated energy input levels of horizontally (blue) and vertically (orange) printed samples. The mean and 95\% CI are depicted by markers and error bars, respectively.

TABle 3: Adjusted $R$-squared values (\%) of the response functions.

\begin{tabular}{lcc}
\hline & & $R^{2}(\mathrm{adj})$ \\
\hline \multirow{2}{*}{ Tensile strength } & $0^{\circ}$ & $96.37 \%$ \\
& $90^{\circ}$ & $78.83 \%$ \\
Tensile modulus & $0^{\circ}$ & $95.52 \%$ \\
& $90^{\circ}$ & $69.90 \%$ \\
Elongation at break & $0^{\circ}$ & $86.35 \%$ \\
Part density & $90^{\circ}$ & $71.39 \%$ \\
& $0^{\circ}$ & $96.45 \%$ \\
\hline
\end{tabular}

value of $0.60 \mathrm{~J} / \mathrm{mm}^{3}$ (upper limit) an increase in energy input will mainly cause a decrease of part accuracy instead of contributing to the quality of the sintered part.

4.4. Response Functions and Sensitivity Analysis. Based on the measured part properties, correlations have been defined using second-order regression equations (based on the methodology as described Section 3.4).

All equations contain five linear terms, which proves that the investigated parameters all have a significant influence on the resulting part properties. The adjusted $R$-squared values (see Table 3) show that the predictive value of the response equations for the part properties of horizontally built samples is high. The adjusted $R$-squared values of the properties along the vertical axis are lower due to the less stable performance of vertically built samples which is caused by anisotropy.

The absolute influence of each parameter on the part properties is given in Figure 7.

The linear correlation coefficients obtained with (6) show that scan spacing and layer thickness have the highest influence on the part property for the majority of the properties, closely followed by scan speed. The linear correlation coefficients of these three parameters are negative, which means that an increase in parameter value has a negative effect on the response value. Preheating temperature and laser power have the lowest yet still significant influence on the part properties. The linear correlation coefficients of these parameters are positive for the majority of the responses. This contradicts the implication made by Caulfield et al. [2] that laser power is the main parameter that affects the part quality and complements the results found by Negi et al. [5] by including the layer thickness as an important process parameter in addition to the scan spacing and scan speed.

Translating the linear correlation coefficients into percentages shows that the tensile strength is largely ( $>50 \%$ ) determined by the scan spacing and the layer thickness. The third and fourth main effects were the scan speed and preheating temperature followed by the laser power.

When analysing the behaviour of the tensile modulus in more detail, a saw-tooth pattern was observed (Figure 6). The peaks of this saw-tooth pattern correspond to parameter sets printed with the smallest layer thickness, while the low values 

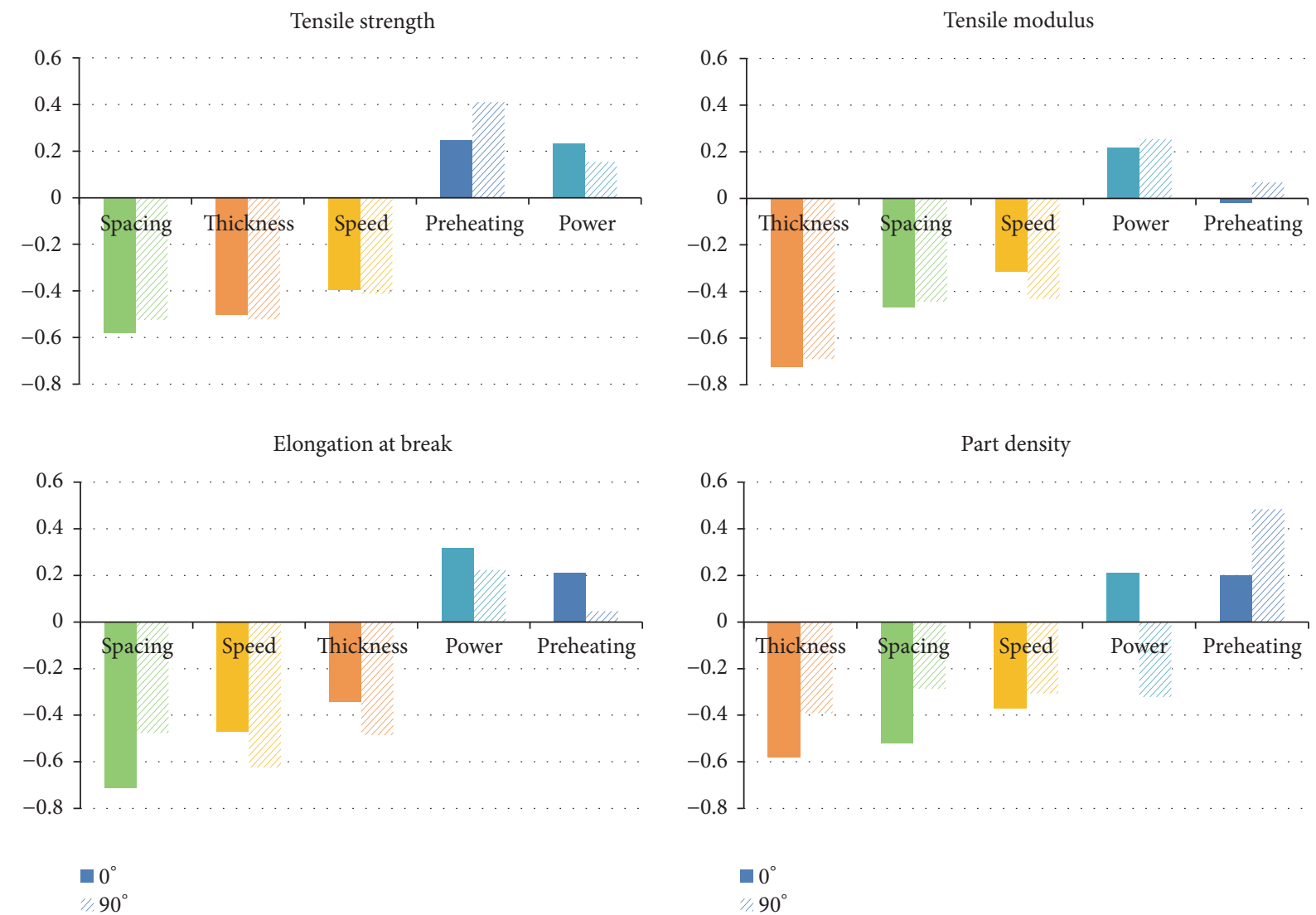

FIGURE 7: Linear correlation coefficients between the process parameters and the resulting part properties, sorted by size.

correspond to parameter sets printed with the thickest layers. The linear correlation coefficients and the corresponding sensitivities confirm that the layer thickness had the largest influence on the tensile modulus for both build orientations. As visualized in Figure 8, the layer thickness determines approximately $40 \%$ of the value for the tensile modulus. The second main effect was the scan spacing, followed by the scan speed and laser power. According to the sensitivity analysis the preheating temperature had a very minimal effect on the tensile modulus (1 to $4 \%$ ).

The elongation at break increased approximately linearly with an increase in energy input. According to the sensitivity analysis, elongation at break was mainly determined by scan spacing and scan speed. The third main effect was layer thickness, followed by laser power and preheating temperature.

The adjusted $R$-squared value of the elongation at break equations is low compared to the other equations. This indicates that there might be another (not investigated) parameter which affects the elongation at break. The expectation is that this parameter is the cooling rate. The cooling rate determines the crystallinity of the material which affects the strain behaviour. Fast cooling results in low crystallinity, high ductility, and large elongation at break. Slow cooling results in high crystallinity, low ductility, and small elongation at break. Implementation of the cooling rate in the regression equation might improve the adjusted $R$-squared value of the elongation at break regression equations.
The graph in Figure 6 showed that the part density is very constant (minimal variability) and stabilizes quickly. Sensitivity analysis of horizontally built samples showed that layer thickness, scan spacing, and scan speed, respectively, determined the majority of the part density value, followed by the laser power and preheating temperature. This behaviour is comparable with the results of the sensitivity analyses of the other part properties. The sensitivity analysis of vertically built samples, however, led to different results. According to the analysis, preheating temperature had the largest effect on the part density of vertically built samples, followed by layer thickness and laser power. All other analyses showed that preheating temperature and laser power had the least significant effect. This deviation could be related to the stable behaviour of the part density. When a property does not (significantly) change despite varying input parameters, it is more complicated to assign an effect to a specific parameter.

\section{Conclusion}

Present work quantified the part properties of 480 tensile samples produced with 17 different parameter sets. The design parameters were the preheating temperature, laser power, scan speed, scan spacing, layer thickness, and part build orientation. The part properties selected as output were the tensile strength, tensile modulus, elongation at break, and part density. Based on the measured data, a regression analysis was performed to obtain the response surfaces for the 

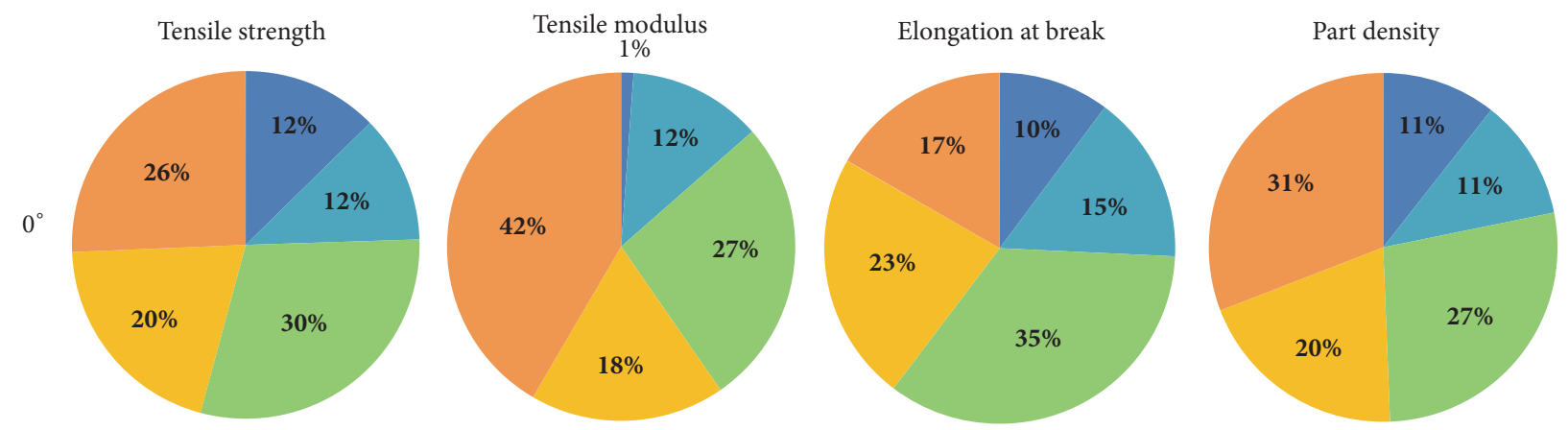

(a)
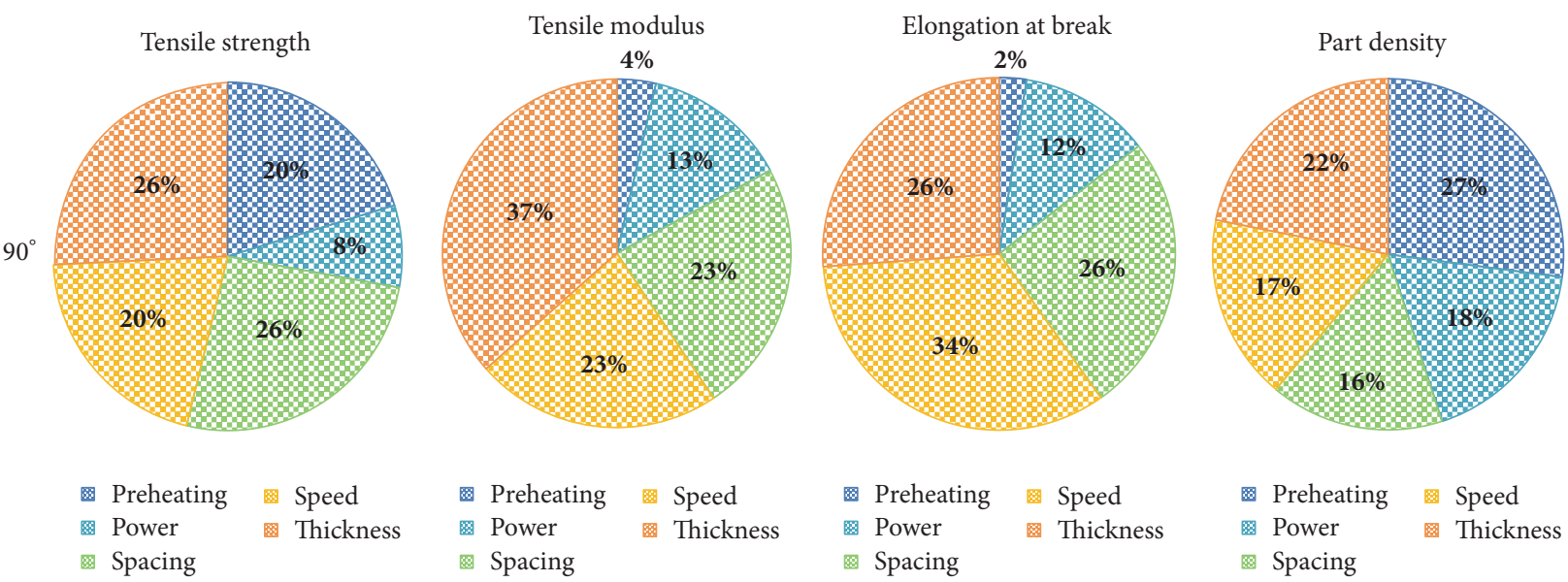

(b)

FIGURE 8: Sensitivities of the process parameters on part properties of horizontally built samples (a) and vertically built samples (b).

part properties. The Monte Carlo simulation was performed using lattice hypercube sampling to determine the linear correlation coefficients and the sensitivities of the process parameters.

Analysis of the part properties versus the energy input showed that the part properties increased with increasing energy input, until an upper limit was reached. In addition, the experiments showed that despite similar density values, the tensile properties of sintered products are directionally dependent. High energy input levels will decrease this anisotropy but will negatively affect the dimensional accuracy of the sintered parts.

Sensitivity analyses showed that the most important process variables were scan spacing and layer thickness. Adjusting the settings of these variables will heavily affect the resulting part properties. Scan speed has the third largest impact on the part properties, followed by preheating temperature and laser power. However, the part density of vertically built samples was affected most by the preheating temperature (see Figures 7 and 8 ). For the elongation at break the second largest $\left(0^{\circ}\right)$ and largest $\left(90^{\circ}\right)$ impact was the scan speed with linear correlation coefficients of -0.47 and -0.62 .

\section{Competing Interests}

The authors declare that there is no conflict of interests regarding the publication of this paper.

\section{Acknowledgments}

The authors would like to thank the 3D printing professional Oceanz for their contribution regarding sample production. In addition special thanks are due to Dr. Ir. M. P. M. A. Limpens (TNO), Dr. Ir. E. Meinders (TNO), and Dr. E. van der Garde (Oceanz) for their input and support.

\section{References}

[1] S. Griessbach, R. Lach, and W. Grellmann, "Small series production of high-strength plastic parts," Kunststoffe International, vol. 98, no. 5, pp. 11-14, 2008.

[2] B. Caulfield, P. E. McHugh, and S. Lohfeld, "Dependence of mechanical properties of polyamide components on build parameters in the SLS process," Journal of Materials Processing Technology, vol. 182, no. 1-3, pp. 477-488, 2007.

[3] R. D. Goodridge, C. J. Tuck, and R. J. M. Hague, "Laser sintering of polyamides and other polymers," Progress in Materials Science, vol. 57, no. 2, pp. 229-267, 2012.

[4] A. Wegner and G. Witt, "Correlation of process parameters and part properties in laser sintering using response surface modeling," Physics Procedia, vol. 39, pp. 480-490, 2012.

[5] S. Negi, S. Dhiman, and R. K. Sharma, "Determining the effect of sintering conditions on mechanical properties of laser sintered glass filled polyamide parts using RSM," Measurement, vol. 68, pp. 205-218, 2015. 
[6] A. E. Tontowi and T. H. C. Childs, "Density prediction of crystalline polymer sintered parts at various powder bed temperatures," Rapid Prototyping Journal, vol. 7, no. 3, pp. 180-184, 2001.

[7] S. Griessbach, R. Lach, and W. Grellmann, "Structure-property correlations of laser sintered nylon 12 for dynamic dye testing of plastic parts," Polymer Testing, vol. 29, no. 8, pp. 1026-1030, 2010.

[8] A. Pilipović, B. Valentan, T. Brajlih et al., "Influence of laser sintering parameters on mechanical properties of polymer products," in Proceedings of the 3rd International Conference on Additive Technologies, January 2010.

[9] S. Berretta, O. Ghita, and K. E. Evans, "Morphology of polymeric powders in Laser Sintering (LS): from Polyamide to new PEEK powders," European Polymer Journal, vol. 59, pp. 218-229, 2014.

[10] U. Ajoku, N. Hopkinson, and M. Caine, "Experimental measurement and finite element modelling of the compressive properties of laser sintered Nylon-12," Materials Science and Engineering: A, vol. 428, no. 1-2, pp. 211-216, 2006.

[11] J. C. Nelson, Selective laser sintering: a definition of the process and an empirical sintering model [doctoral dissertation], University of Texas, Austin, Tex, USA, 1993.

[12] L. Thijs, F. Verhaeghe, T. Craeghs, J. V. Humbeeck, and J.P. Kruth, "A study of the microstructural evolution during selective laser melting of Ti-6Al-4V," Acta Materialia, vol. 58, no. 9, pp. 3303-3312, 2010.

[13] R. J. M. M. Does, G. B. W. van Dongen, and A. Trip, An Introduction to Design of Experiments in Industry, CQM, Eindhoven, The Netherlands, 1992.

[14] J. K. Telford, "A brief introduction to design of experiments," Johns Hopkins APL Technical Digest, vol. 27, no. 3, pp. 224-232, 2007.

[15] "Minitab 17, Multiple Regression," http://support.minitab.com/ en-us/minitab/17/Assistant_Multiple_Regression.pdf.

[16] I. Baran, C. C. Tutum, and J. H. Hattel, "Probabilistic analysis of a thermosetting pultrusion process," Science and Engineering of Composite Materials, vol. 23, no. 1, pp. 67-76, 2016.

[17] D. G. M. Wright, R. Dunk, D. Bouvart, and M. Autran, “The effect of crystallinity on the properties of injection moulded polypropylene and polyacetal," Polymer, vol. 29, no. 5, pp. 793796, 1988.

[18] A. K. Van der Vegt, Polymeren: van Keten tot Kunststof, Delft University Press, Delft, Netherlands, 1991.

[19] H. Zarringhalam, N. Hopkinson, N. F. Kamperman, and J. J. de Vlieger, "Effects of processing on microstructure and properties of SLS Nylon 12," Materials Science and Engineering A, vol. 435436, pp. 172-180, 2006.

[20] Y. Shi, Z. Li, H. Sun, S. Huang, and F. Zeng, "Effect of the properties of the polymer materials on the quality of selective laser sintering parts," Proceedings of the Institution of Mechanical Engineers, Part L: Journal of Materials: Design and Applications, vol. 218, no. 3, pp. 247-252, 2004. 

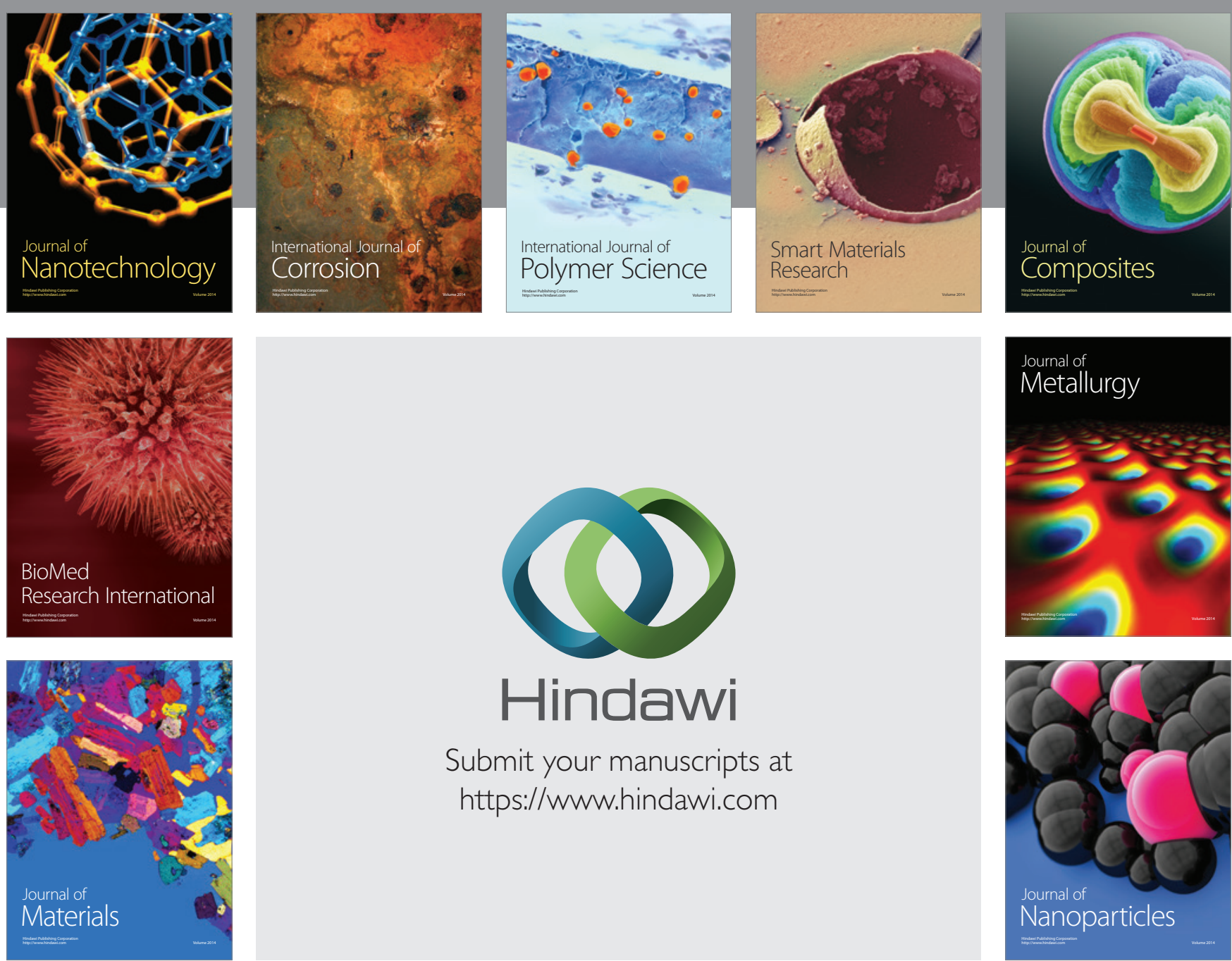

\section{Hindawi}

Submit your manuscripts at

https://www.hindawi.com

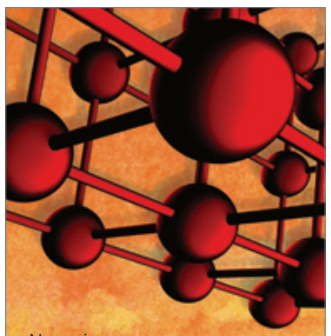

Materials Science and Engineering
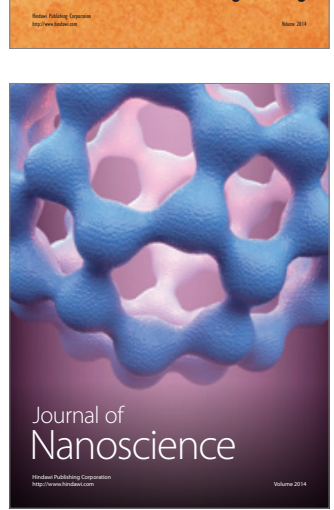
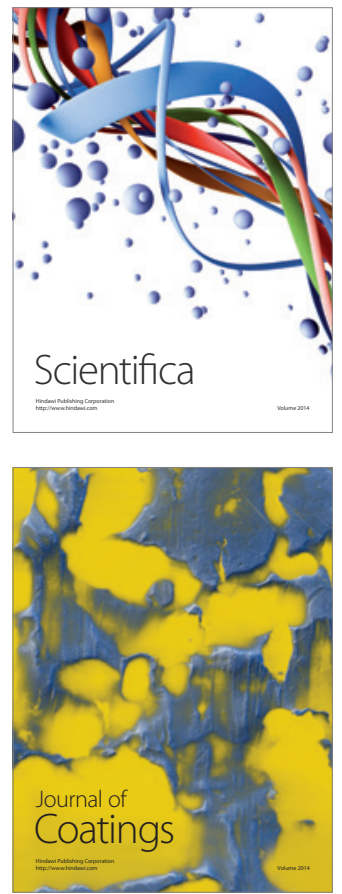
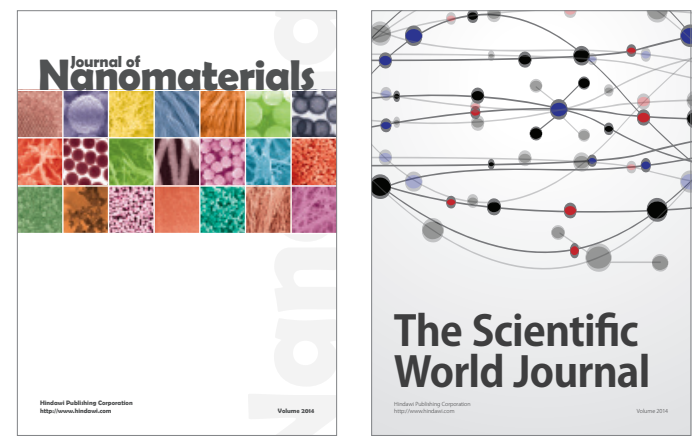

The Scientific World Journal
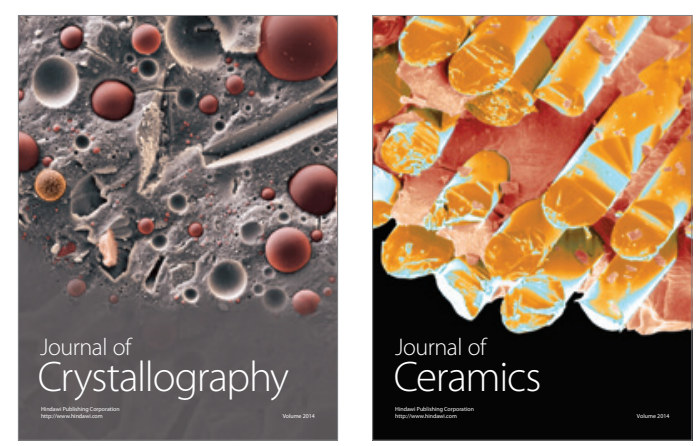
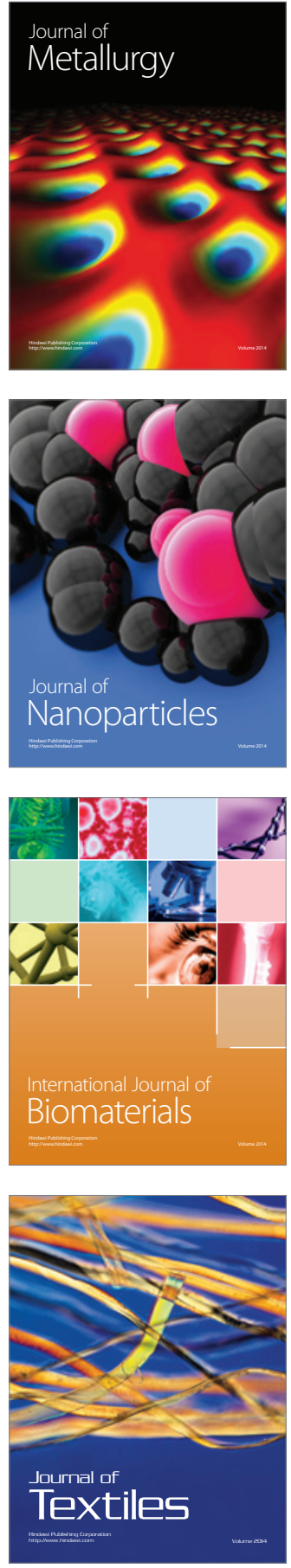